\title{
Time of day impacts on machine productivity and value recovery in an off-forest central processing yard
}

\author{
Glen Murphy ${ }^{1 *}$, Hamish Marshall ${ }^{2}$ and Andy Dick ${ }^{3}$
}

\begin{abstract}
Background: Effective use of the high capital cost equipment in a central processing yard requires a good understanding of the human component of the system. Poorly designed work schedules have been linked with mental and physical fatigue of the machine operators, low productivity and low value recovery for some operations. The aim of this study was to determine if time of day impacts machine productivity and value recovery in an off-forest central processing yard.
\end{abstract}

Methods: A database, containing over 120,000 records on Pinus radiata D.Don (radiata pine) stems processed during 214 work shifts, was analysed in order to determine the impact of time of day on value recovery and productivity of log-handling equipment that consisted of a scanning optimiser and two mechanised processors operating in an off-forest central processing yard in New Zealand.

Results: Analyses indicate time of day negatively impacted volume productivity and value recovery for the scanning optimizer between the first shift operating mainly in daylight hours and the second shift operating mainly during night hours. There were no clear trends in productivity for the mechanised processors.

Conclusions: These findings are in agreement with an earlier study carried out in on-forest mechanised harvesting operations in Chile but differ from findings of another off-forest central processing yard in New Zealand.

Keywords: Work shifts; Mechanised processing; Central processing yards; Human factors; Productivity; Value recovery

\section{Background}

Traditionally, initial assessment of logs in New Zealand has occurred at landing areas in the forest close to felling operations. Another approach used intermittently in New Zealand for over forty years has been to transport logs to a central processing yard (CPY), sometimes called a log-sort yard. Purported advantages of centralised processing include the provision of many wood-marketing and value-capturing services via concentrating, merchandising, processing, and sorting of logs (Dramm et al. 2004). Additional advantages may include savings in road construction and transportation costs, reduced logging and landing construction costs, reduced environmental impacts resulting from

\footnotetext{
* Correspondence: glen.murphy@waiariki.ac.nz

'Waiariki Institute of Technology, Rotorua, New Zealand

Full list of author information is available at the end of the article
}

smaller landings, improved utilisation of logging residues, and greater opportunities resulting from artificial lighting to work longer hours in a yard than in a forest (McKerchar \& Twaddle 1987).

Extended working schedules (i.e. those longer than a standard eight hours) are commonly used in the sawmilling and pulping sectors of the forest industry globally but have had mixed success in the harvesting, stem conversion, and transportation sectors. They have been tried and discarded in some parts of the world but have been used successfully for many years in other parts. Extended work schedules may include working more hours per shift, multiple shifts per day, more days per week, or some combination of these. Increasing production capacity, production efficiency and monetary returns are reasons given for operating extended hours. 
Depending on their design, CPYs can require high capital outlays. Effective use of the high capital cost equipment in a CPY (or in forest operations) requires a good understanding of the human component of the system. Kirk (1998) noted that studies worldwide have linked poorly designed work schedules with mental and physical fatigue, low productivity and low value recovery. Many researchers from a wide range of industries, including forestry, have found that hourly production declines as shift length increases (Vernon 1921, Golsse 1991, Nevison 1992, Hanna et al. 2005, Passicot \& Murphy 2013). Productivity can also be lower for night shifts than for day shifts. Kerin and Carbone (2003) reported an average drop in productivity of $5 \%$ for night shifts across all major U.S. industries based on surveys of employees and managers from over 1000 companies. Studies of forest harvesting operations in North America and Australasia reported declines in hourly productivity as high as $40 \%$ for night shifts compared with day shifts (Maxwell 1982, Nicholls et al. 2004, Mitchell 2008).

Murphy and Vanderberg (2007) noted that, while there was potential for a reduction in costs resulting from increased daily production by working extended hours, the size of the production increase was sometimes insufficient for cost reductions to be realised. The impacts of extended hours on other tangible and intangible costs such as value recovery losses and human factors (e.g. employee-turnover rates, accident risk, and the opportunity for employees to participate in social and domestic activities) need to be considered (Mitchell 2008).

Research on hundreds of World War I munitions factory workers in the United Kingdom by Vernon (1921) allowed him to examine the effects on productivity of a wide range of factors, including age, sex, season of the year, length of shift, and time of day. As a result of his research, he recommended studying as large a group of workers as possible over as long a period as possible when investigating output from alternative work schedules in order to remove physical and psychological factors for individual workers,. He also commented on the use of indirect observations (e.g. taking measurements from machines being used by the workers) to supplement direct observations. These recommendations were made because: (1) there is wide variability in the time of day at which humans perform at their best; and (2) the action of being observed may positively or negatively influence the performance of the observee ("observer" effect) for short-duration studies.

This paper reports the results of a case study on the effects of extended working hours on the productivity and value recovery of an off-forest, central processing yard in New Zealand. Results are based on long-term data that have been collected by indirect methods.

\section{Methods}

Pan Pac Forest Products Limited (Pan Pac) is an integrated forest products company that owns 33,000 hectares of forest plantation on the east coast of the North Island of New Zealand. Their Forestry and Logistics Division manages an annual volume of 1.5 million $\mathrm{m}^{3}$ of which about 0.75 to 0.90 million $\mathrm{m}^{3}$ comes from their own estate. Pan Pac produces pulp, timber, export chip and export logs from its operations.

In 2004, Pan Pac began operating a processing yard "3PY" (Pan Pac Processing Yard), attached to their timber and pulp-processing plants. The 3PY is well lit with overhead floodlights. Delimbed stems, or stem segments, are transported in trucks from the company's forests to the 3PY. Stems are unloaded from the trucks and stored in stockpiles. Stems are retrieved from the stockpiles as needed and are then passed through a three-(or four-) machine mobile optimising plant, known as Logmeister. This plant consists of a loader, a scanner/optimiser and one or two log-bucking machines. The person operating the loader selects a delimbed stem and then places it onto the platform of the scanner/optimiser. A scanner cab moves parallel to the stem and generates a stem profile (up to $38 \mathrm{~m}$ in length) (Figure 1). A second person (the scanner operator) then manually enters changes in wood-quality codes along each stem into the scanner. The stem profile with the overlain quality codes is then virtually bucked using the Logmeister optimiser algorithm. A stem-identification number is manually marked on the butt of each stem by the loader operator, who then moves the scanned stem aside and loads another stem. The stem profile and quality codes are wirelessly transmitted to a log-bucking machine with a processing head mounted on an excavator base. This machine collects the scanned stem and one or two processors cut the $\log$ as prescribed by the Logmeister scanner. Since stems are individually identified, they do not have to be bucked in any particular order. Cutting strategies and log-grade prices are relayed from company offices wirelessly and all production data are uploaded, instantly, to a remote server. Reports are available via internet and directly through Structured Query Language (SQL) queries. The time of day, identity of machine operators, number of quality codes used, and stem attributes measured are automatically recorded for each stem that is scanned or processed.

This study included the scanner operators and the logbucking processors but excluded the loader operators. The Logmeister system is in operation five days per week with two shifts per day. The first shift for the scanner operator is a fixed length of 9.5 hours and runs from $4.00 \mathrm{am}$ to $1.30 \mathrm{pm}$. Minor maintenance and refuelling can be done between $1.30 \mathrm{pm}$ and $2.00 \mathrm{pm}$ by operators from the first shift. The second shift is open-ended. It 


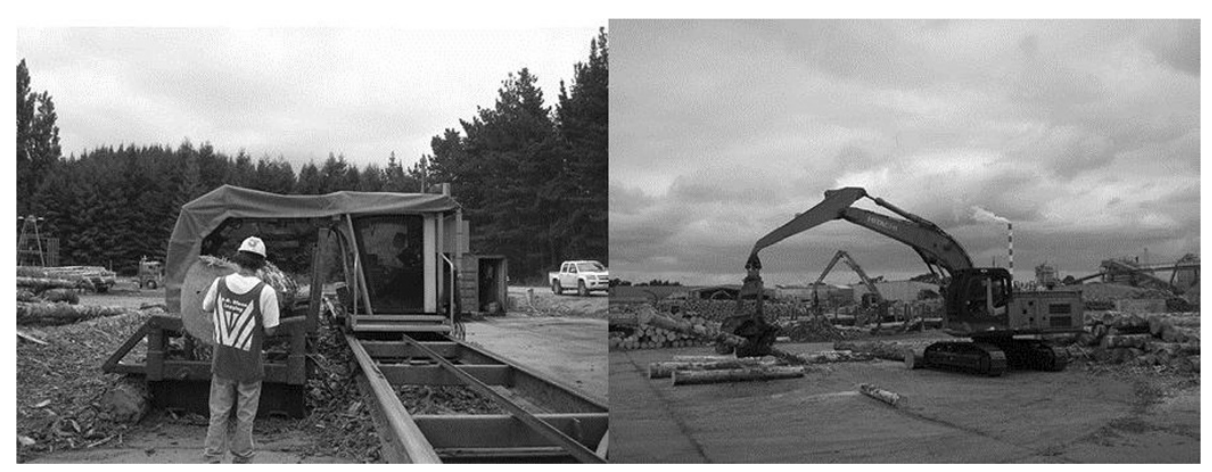

Figure 1 The Logmeister scanner (left) runs on rails parallel to the log and virtually bucks the stem. The bucked stem solution is wirelessly passed to a second machine (right) with a processor head which cuts the stems into logs.

runs from $2.00 \mathrm{pm}$ until the time when all the stems produced from the forest estate that day have been scanned. This is often around $10.00 \mathrm{pm}$ but can extend to 3.00 am the following day. A single scanner operator is scheduled for each shift, but scanner operators sometimes swap roles with other machine operators or manual workers. One, sometimes two, processors are scheduled to cut the stems into logs per shift. Shift lengths for the processors vary from 8 to 12 hours. One 30-minute rest- and meal-break per shift is taken by both scanner and processor operators. Competition exists among workers between the first and second shifts about who can produce the most wood volume per shift. Although not company policy, there was a tendency during this study for the loader operators from both shifts to feed bigger stems into the system at the beginning of the shift to quickly build up volume, and the smaller stems were left over towards the end of the shift.

Data records from early January 2011 through to the end of May 2011 were extracted from the Logmeister database for analysis. During this period, 120,807 radiatapine stem pieces with a total volume of $246,844 \mathrm{~m}^{3}$ were scanned and processed over 200 work shifts. Piece lengths ranged from 1.27 to $20.11 \mathrm{~m}$ (mean $12.60 \mathrm{~m}$ ). Piece volumes ranged from 0.04 to $11.03 \mathrm{~m}^{3}$ (mean $2.04 \mathrm{~m}^{3}$ ).
Seven people operated the scanner during the study period. Two of these have been excluded from the analyses because they scanned very few $(0.3 \%)$ of the total number of pieces. The proportions of the remaining $99.7 \%$ of the pieces scanned by each of the remaining five operators are given in Table 1. Three of the scanner operators were women and two were men. Their practical experience on the scanner ranged from 0.5 to 4.5 years.

Six people operated the processors cutting the pieces into logs during the study period. One operator was excluded because of the small number of pieces he processed. The remaining five operators processed $99.3 \%$ of the pieces (Table 1). All processor operators were men. Experience on the processors ranged from 1 to 4 years.

Scanner operators and processor operators were all allocated to rotating shift schedules; that is, all scanner operators and all processor operators worked in both the first and second shift at some point during the study period.

Although there were two shifts for machine operators, managers and company and contractor supervisors worked just the traditional "9 am to $5 \mathrm{pm}$ " day. Production and value performance was scrutinised more intensively during the hours that managers and supervisors worked.

Production data from the Logmeister database were imported into a Microsoft Excel ${ }^{\mathrm{m} t}$ spreadsheet. Production

Table 1 Number of pieces scanned or processed per machine operator

\begin{tabular}{|c|c|c|c|c|c|}
\hline \multicolumn{3}{|c|}{ Scanning } & \multicolumn{3}{|c|}{ Processing } \\
\hline Operator ID & Number of pieces & Proportion of total (\%) & Operator ID & Number of pieces & Proportion of total (\%) \\
\hline A & 18067 & 15.0 & $\mathrm{~F}$ & 6431 & 5.3 \\
\hline B & 17643 & 14.6 & G & 25999 & 21.5 \\
\hline C & 35681 & 29.5 & $\mathrm{H}$ & 18535 & 15.3 \\
\hline D & 43042 & 35.6 & 1 & 35819 & 29.6 \\
\hline $\mathrm{E}$ & 5985 & 5.0 & J & 33151 & 27.4 \\
\hline Sub-total & 120418 & 99.7 & Sub-total & 119935 & 99.3 \\
\hline Others & 389 & 0.3 & Others & 872 & 0.7 \\
\hline Total & 120807 & 100.0 & Total & 120807 & 100.0 \\
\hline
\end{tabular}


data included piece count, piece lengths, volume, quality codes called by the scanner operator, time to scan, and time to process pieces. The database did not include reporting of major delays, nor their causes. Pivot tables were then used to summarise the production data by time of day (hourly intervals), operation (scanning or processing), operator identity (ID), and first shift/second shift classification. Multiple regression analysis, using indicator variables, was used to examine the effect of key parameters (e.g. operator ID, time of day, average stem size) on machine productivity $\left(\mathrm{m}^{3} \mathrm{~h}^{-1}\right)$. A parameter was considered to be significant if the $p$-value was less than 0.05 .

Value recovered during the study period depended on the prevailing market conditions including what logs types were being cut on a particular day and what the relative prices were for each log type being cut. Changes in markets were accounted for by virtually re-bucking the scanned stems using a standard set of log types and prices as specified in Table 2. The standard set included log types that the scanner operators and processor operators were all familiar with. Only pieces greater than $10 \mathrm{~m}$ in length and scanned by one of the five operators listed in Table 1 were included in the value recovery analyses. These 70564 pieces accounted for $58 \%$ of the total pieces scanned and $70 \%$ of the value recovered under prevailing market conditions. Value data were imported into an Excel $^{\mathrm{si}}$ spreadsheet. Pivot tables were again used to summarise the data by time of day, shift, and operator ID. Multiple regression analysis was used to examine the effect of key parameters on value recovery $\left(\$ \mathrm{~m}^{-3}\right)$.

\section{Results}

\section{Scanning productivity}

The total number of stems scanned during the first 9.5-hour shift (47\%) was similar to the number scanned during the first 9.5 hours $(2.00-11.30 \mathrm{pm})$ of the second shift (46\%). The remaining $7 \%$ of the stems were scanned in the five hours between $11.30 \mathrm{pm}$ and 4 am the following morning. These late evening/early morning hours were worked only when not doing so would have resulted in an "insufficient" stockpile of scanned stems to meet processor and mill needs for the beginning of the following day.

Piece-count productivity (pieces $\mathrm{h}^{-1}$ ) varied throughout the day (Figure 2). There was a tendency for productivity to rise by about $20 \%$ at the beginning of the shift and fall at the end of the shift; $r^{2}$ values for second order polynomials fitted to the mean productivity data, excluding rest breaks and shift changes, were 0.38 and 0.50 for Shifts 1 and 2 respectively. As expected, productivity was lower during the hours when rest breaks and shift changes occurred. There was also a drop in productivity at around $8 \mathrm{pm}$ in the second shift. This was not due to a scheduled break and the authors were unable to determine the cause of the drop from the available data. Hourly piece count productivity was $9 \%$ higher during the second shift than the first shift; 61 and 56 pieces $\mathrm{h}^{-1}$ respectively. Piece count productivity trends are complicated by the fact that the average piece size scanned gradually dropped throughout each shift; by about 20\% for Shift 1 and by about $40 \%$ for Shift 2 . On a per cubic metre basis, the average number of quality codes called ranged from 0.5 to 4.3 and the average time to cruise a piece ranged from 14 to $60 \mathrm{sec}-$ onds. Both the number of quality codes called per cubic metre and the cruising time per cubic metre decreased as the average piece size increased. Regression analysis showed that the main causes of the difference between Shift 1 and Shift 2 hourly piece count productivity were average stem size and other variables (i.e., operator effects, and scheduled break and end-of-shift effects). Once these were taken into account, time of day had no significant effect on piece count productivity (Table 3).

Table 2 Log specifications and prices used in the value recovery analyses

\begin{tabular}{|c|c|c|c|c|c|}
\hline Grade & Length (m) & Relative Price $\left(\$ \mathrm{~m}^{-3}\right)$ & $\begin{array}{l}\text { Maximum branch } \\
\text { diameter }(\mathrm{cm})\end{array}$ & $\begin{array}{l}\text { Minimum small } \\
\text { end diameter }(\mathrm{cm})\end{array}$ & $\begin{array}{l}\text { Maximum } \\
\text { sweep }^{1}\end{array}$ \\
\hline Pruned domestic & 4.98 & 134 & 0 & 35 & SED/4 \\
\hline Pruned domestic & 4.08 & 128 & 0 & 35 & SED/4 \\
\hline A-grade export & 3.92 & 113 & 10 & 32 & SED/4 \\
\hline A-grade export & 3.12 & 112 & 10 & 32 & SED/4 \\
\hline K-grade export & 3.92 & 106 & 10 & 24 & SED/4 \\
\hline K-grade export & 3.12 & 105 & 10 & 24 & SED/4 \\
\hline s2-grade domestic & 5.50 & 96 & 7 & 32 & SED/4 \\
\hline s3-grade domestic & 5.50 & 92 & 7 & 23 & SED/4 \\
\hline L1-grade domestic & 4.68 & 83 & 15 & 42 & $\mathrm{SED} / 4$ \\
\hline L2-grade domestic & 4.68 & 82 & 15 & 32 & SED/4 \\
\hline Pulp & $2.4-6.0$ & 51 & 99 & 10 & $\mathrm{SED} / 2$ \\
\hline
\end{tabular}

${ }^{1}$ Maximum allowable sweep is expressed as a function of the small end diameter (SED). 


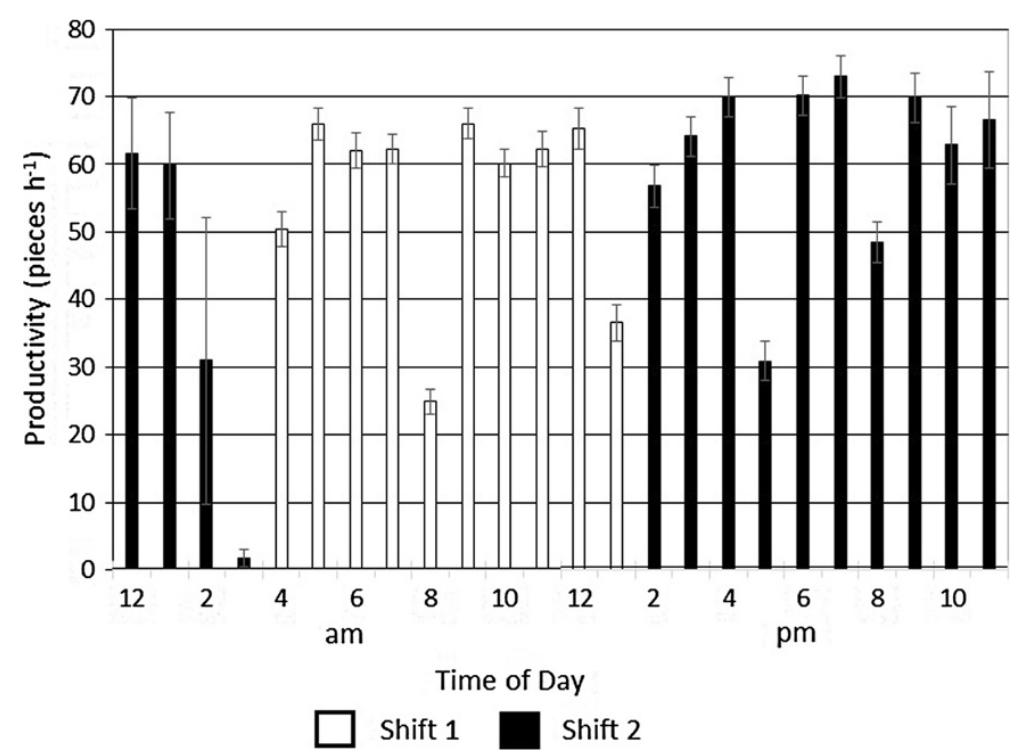

Figure 2 Average scanning machine productivity over a 24-hour period. Error bars show 95\% confidence limits.

Analysis of the data showed that hourly scanner volume productivity was significantly higher during the first shift than the second shift of the day; 123 and $114 \mathrm{~m}^{3} \mathrm{~h}^{-1}$ respectively. For one third of the hours included in the analysis, two or more operators shared the task of scanning stems. Also, most of the sharing of the scanning task (79\%) took place during the first shift. Regression analysis (Table 4) indicated that volume productivity increased as average size being handled increased. However, volume productivity was $33 \mathrm{~m}^{3} \mathrm{~h}^{-1}$ lower during those hours in which scheduled breaks or end-of-shift activities occurred, and was 10 to $17 \mathrm{~m}^{3} \mathrm{~h}^{-1}$ lower when a single operator scanned logs during an hour than when two or more operators shared the scanning role. Once these confounding effects were accounted for time of day was found to have a negative effect on hourly productivity; falling by about $1 \mathrm{~m}^{3}$ for each hour of the day.

\section{Processor productivity}

The average stem size processed was not consistent throughout the day (Figure 3). There was a trend for stem size to fall gradually between midnight and $2.00 \mathrm{pm}$; increase rapidly to $4.00 \mathrm{pm}$, then fall gradually again to midnight. The number of stems processed per hour followed the reverse trend.

The analysis of time of day impacts on processing productivity is further complicated by the fact that one processing machine was used for $59 \%$ of the time and two machines were used for $41 \%$ of the time. There was no evidence to indicate that dual processing machine activity was concentrated at particular times of the day; two machines were used whenever processing productivity fell too far behind scanning productivity. As expected, when two machines were used processing productivity was significantly higher than when one machine was used; 41 to

Table 3 Regression model for scanning piece count productivity (pieces $\mathbf{h}^{-1}$ )

\begin{tabular}{lllll}
\hline Variable $^{\mathbf{1}}$ & Coefficient & Standard error & t-statistic & p-value \\
\hline Intercept & 94.2 & 1.4 & 69.5 & $<0.00001$ \\
Stem size & -13.2 & 0.6 & -23.8 & $<0.00001$ \\
Group A operators & -3.0 & 0.9 & -3.4 & 0.00067 \\
Group B operators & -4.6 & 0.9 & -5.0 & $<0.00001$ \\
SBandE $^{2}$ & -21.8 & 0.9 & -25.1 & $<0.00001$
\end{tabular}

${ }^{1}$ Stem size is the average stem size $\left(\mathrm{m}^{3}\right)$ scanned during each hour. Group A and Group B operators were indicator variables for single operators whose productivity was different from members within other groups, but not with members in the same group. Note that the default operator value was when two or more people scanned stems within the same hour.

${ }^{2}$ SBandE was an indicator variable for those hours in which a scheduled break occurred or in which end-of-shift work was undertaken. 
Table 4 Regression model for scanning volume productivity $\left(\mathrm{m}^{3} \mathrm{~h}^{-1}\right)$

\begin{tabular}{|c|c|c|c|c|}
\hline Variable $^{1}$ & Coefficient & Standard error & t-statistic & $p$-value \\
\hline Intercept & 52.4 & 5.4 & 9.7 & $<0.00001$ \\
\hline Stem size & 28.9 & 1.7 & 16.8 & $<0.00001$ \\
\hline Group A operators & -10.3 & 2.4 & -4.4 & 0.00001 \\
\hline Group B operators & -17.2 & 2.4 & -7.0 & $<0.00001$ \\
\hline SBandE $^{2}$ & -33.4 & 2.4 & -14.1 & $<0.00001$ \\
\hline Time of day ${ }^{3}$ & -1.0 & 0.2 & -5.7 & $<0.00001$ \\
\hline Total degrees of freedom & & F statistic & & Adjusted R Square \\
\hline 1890 & & 129.1 & & 0.254 \\
\hline
\end{tabular}

${ }^{1}$ Stem size is the average stem size $\left(\mathrm{m}^{3}\right)$ scanned during each hour. Group A and Group B operators were indicator variables for single operators whose productivity was different from members within other groups, but not with members in the same group. Note that the default operator value was when two or more people scanned stems within the same hour.

${ }^{2}$ SBandE was an indicator variable for those hours in which a scheduled break occurred or in which end-of-shift work was undertaken.

${ }^{3}$ Time of day is based on a 24 -hour clock; e.g. $4=$ from 4.00 to $4.59 \mathrm{am}, 16=$ from 4.00 to $4.59 \mathrm{pm}$, etc.

$57 \mathrm{~m}^{3} \mathrm{~h}^{-1}$ higher depending on operators. Regression analysis indicated that, once the confounding effects of average stem size, usage of dual processing machines, and operator differences were taken into account, time of day had no significant effect on processor hourly volume productivity (Table 5).

\section{Value recovery}

The average value recovered at different times of the day is shown in Figure 4. The average value recovery was very similar, although statistically different, for the first $\left(\$ 87.16 \mathrm{~m}^{-3}\right)$ and second shifts $\left(\$ 86.68 \mathrm{~m}^{-3}\right)$. The effect of piece size on value recovery is shown in Figure 5.

Regression analysis showed that, once the confounding effects of average stem size, hours in which scheduled breaks and end-of-shift activities occurred, and operator differences were taken into account, time of day had a significant effect on scanner value recovery (Table 6). Value recovery fell by an average of $\$ 0.36 \mathrm{~m}^{-3}(\sim 0.4 \%)$ for each hour of the day starting at midnight.

\section{Discussion and conclusions}

No consistent impact of time of day on overall productivity was evident from the data studied. Scanner volume productivity was found to be negatively correlated to the time of day. However, statistically significant impacts on scanner piece count productivity or processor volume productivity due to time of day could not be discerned. Instead, differences were due to average piece size being handled, number of machines being used, or differences between operators.

Rose et al. (2007) found no drop in productivity for the night shift compared with the day shift of a large, non-mobile, centralised processing yard in New Zealand. Very good lighting outside of normal daylight hours was

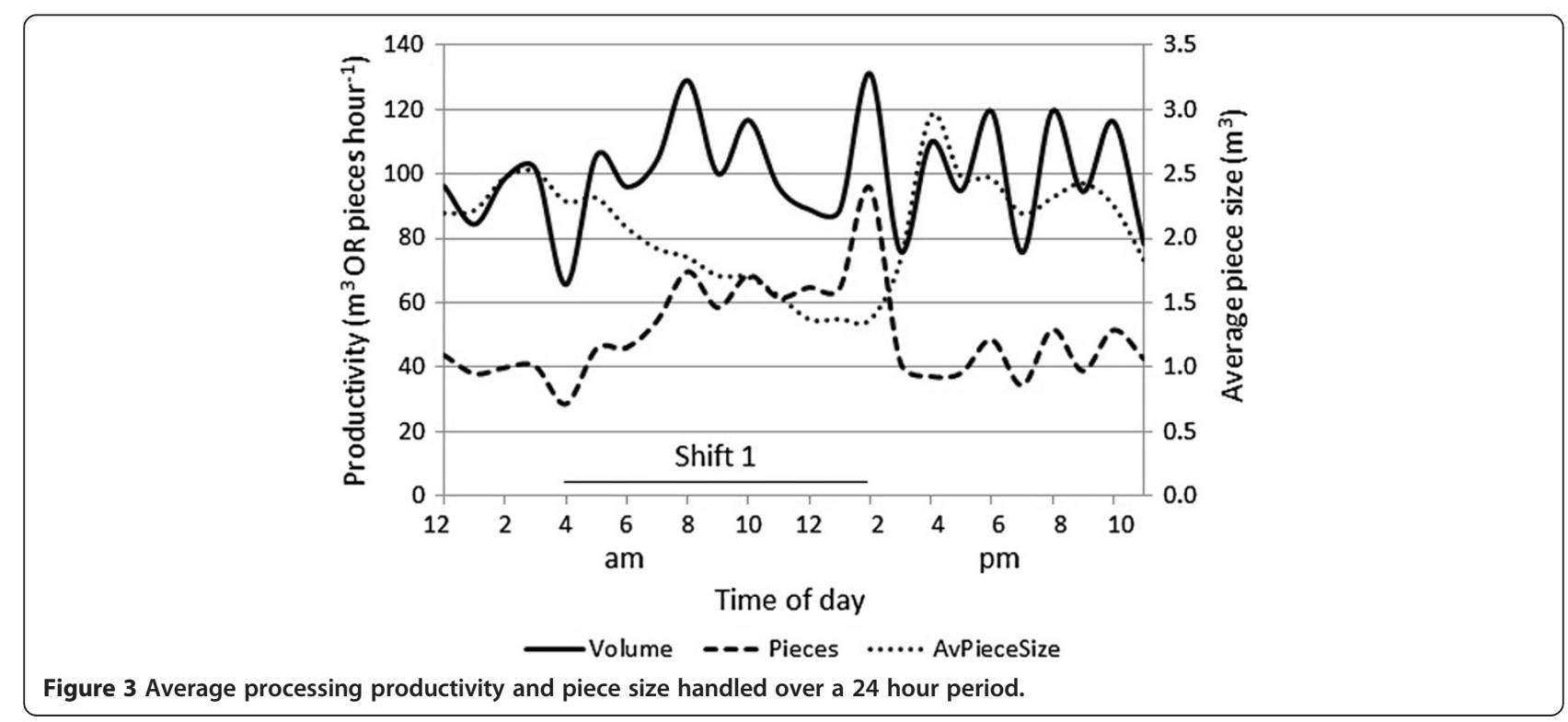


Table 5 Regression model for processor volume productivity $\left(\mathrm{m}^{3} \mathrm{~h}^{-1}\right)$

\begin{tabular}{|c|c|c|c|c|}
\hline Variable $^{1}$ & Coefficient & Standard error & t-statistic & $p$-value \\
\hline Intercept & 79.1 & 2.8 & 28.0 & $<0.00001$ \\
\hline Stem size & 19.3 & 1.2 & 15.8 & $<0.00001$ \\
\hline Group C operators & -57.3 & 2.9 & -19.5 & $<0.00001$ \\
\hline Group D operators & -41.4 & 2.4 & -17.0 & $<0.00001$ \\
\hline
\end{tabular}

${ }^{1}$ Stem size is the average stem size $\left(\mathrm{m}^{3}\right)$ processed during each hour. Group C and Group D operators were indicator variables for single operators whose productivity was different from members within other groups, but not with members in the same group. Note that the default operator value was when two or more machines processed stems within the same hour.

a feature in both the yard studied by Rose et al. (2007) and the current study. The current findings for the processor volume productivity and the scanner piece count productivity are in agreement with those findings of Rose et al. (2007) but not for scanner volume productivity.

The scanner volume productivity results, but not the processor volume productivity results or the scanner piece count results, from the current study of an off-forest central processing yard in New Zealand agree, however, with the findings of a recent study of on-forest mechanised harvesting operations in Chile. The Chilean study showed that productivity $\left(\mathrm{m}^{3} \mathrm{~h}^{-1}\right)$ was negatively affected by working extended hours and/or multiple shifts per day (Passicot \& Murphy 2013). As noted in the Introduction, other researchers have also found shift length and time of day impacts on on-forest operations productivity (Maxwell 1982, Golsse 1991, Nicholls et al. 2004).

The current results indicated both volume productivity and piece count productivity were significantly higher for the hours when two or more operators shared the scanning task than for those hours when a single operator undertook the scanning task. Gellerstedt (1997) noted that Swedish experience has shown that high levels of productivity can be sustained throughout the day by rotating jobs within forest-harvesting crews and by allowing operators to select the day or evening shift that suits them best in a multi-shift operation.

Comment is often made in the literature on the effect of circadian rhythm on error rates which are at their highest between midnight and $6 \mathrm{am}$, peaking in the early hours of the morning (2.00 to $4.00 \mathrm{am}$ ) (Folkard and Tucker 2003, de Mello et al. 2008). It was expected that increased error rates would lead to lower value recovery during this period of the day. In the current case study, value recovery was found to decrease at the rate of about $0.3 \%$ per hour throughout the day between midnight and midnight. The present authors are unable to provide reasons as to why value should continue to drop at the same rate between 6.00 am and midnight. It is worth noting that scanner operators had good overhead lighting and operating conditions,

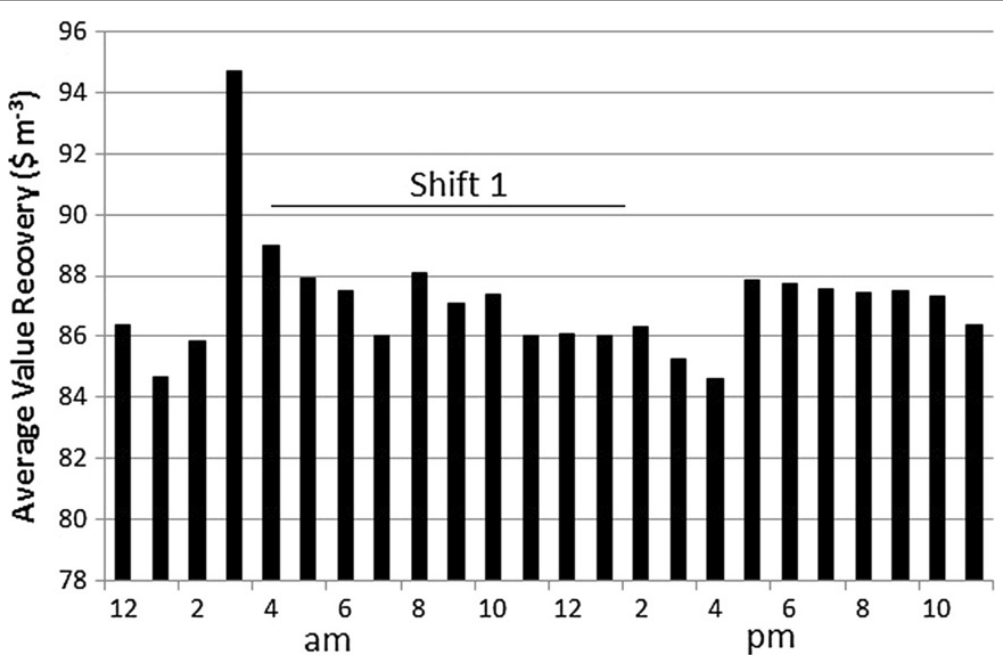

Figure 4 Effect of time of day on average value recovered based on measured stem dimensions, actual quality calls, and virtual bucking of over 70,000 stems by five scanner operators. 


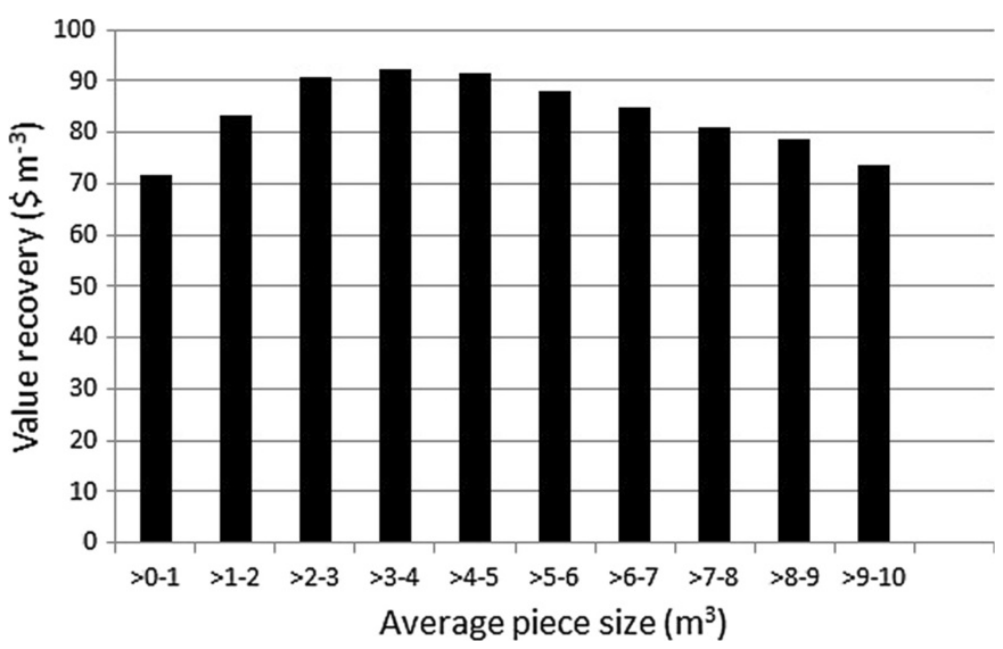

Figure 5 Effect of average piece size on average value recovered.

and the use of scanning optimising software, not the human scanner operator, determined the log-cutting regime. The operator(s) did need to identify and mark changes in quality along the stem but they did not have to decide what log types should be cut. Future research should explore the impact of time of day on value recovery for processors operating on-forest, particularly if these are not fitted with an optimising computer.

Statistically significant differences in value recovery, albeit small ( $5 \%)$, were noted among scanning operators. The range in value recovery among operators is considerably smaller than that reported by Murphy (2002) based on worldwide studies of mechanised operations. This may be due to good operator selection on the part of the Logmeister contractor or due to the use of an optimiser on the scanner requiring fewer log-making decisions by the operator.

As noted in the Introduction, Vernon (1921) recommended using indirect observations gathered over as long a period as possible to study as many people as possible. In this study, indirect observations gathered over a five-month period were used to study five scanner operators and five processor operators. While sample sizes of five are better than one, the operators included in this study may not reflect the true range of forestry machine operator reactions to different work schedule designs. The authors also note, however, that the Logmeister system was the only one of its type operating in New Zealand at the time this study was undertaken and all operators working more than a few hours were included in the study.

Further work is needed on time of day impacts and work schedule design on production economics. Understanding the effects of extended work hours and different work schedules on people, productivity and value recovery of both on- and off-forest mechanised operations will allow planners to better manage log supply, labour force requirements, and the economics of the forest to mill supply chain.

Table 6 Regression model for scanning value recovery $\left(\$ \mathrm{~m}^{-3}\right)$

\begin{tabular}{lllll}
\hline Variable $^{\mathbf{1}}$ & Coefficient & Standard error & t-statistic & p-value \\
\hline Intercept & 7.96 & 2.72 & 2.9 & 0.0035 \\
Stem Size & 57.76 & 1.94 & 29.8 & $<0.00001$ \\
Stem Size Squared & -6.56 & 0.38 & -17.2 & $<0.00001$ \\
Group E Operators & 6.64 & 0.89 & 7.5 & $<0.00001$ \\
SBandE $^{2}$ & 3.77 & 1.09 & 3.4 & 0.00059 \\
Time of Day $^{3}$ & -0.36 & 0.08 & -4.5 & $<0.00001$
\end{tabular}




\section{Competing interests}

$A D$ is the owner of the Logmeister equipment that was used in this study. The equipment operators were wage workers employed by a third party contractor. GM and HM declare that they have no competing interests.

\section{Authors' contributions}

AD participated in the collection and interpretation of the data and assisted with the drafting of the manuscript. HM participated in the preliminary analysis of the data and assisted with the drafting of the manuscript. GM participated in further analysis and interpretation of the data and drafted and revised the manuscript. All authors read and approved the final manuscript.

\section{Author details}

${ }^{1}$ Waiariki Institute of Technology, Rotorua, New Zealand. ${ }^{2}$ Interpine Forestry Ltd, Rotorua, New Zealand. ${ }^{3}$ Logjiztix Ltd, Auckland, New Zealand.

Received: 19 November 2013 Accepted: 31 July 2014

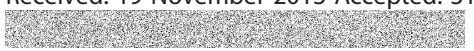

\section{References}

de Mello, MT, Esteves, AM, Pires, MLN, Santos, DC, Bittencourt, LRA, Silva, RS, \& Sufik, S. (2008). Relationship between Brazilian air pilot errors and time of day. Brazilian Journal of Medical and Biological Research, 41, 1129-1131.

Dramm, JR, Govett, R, Bilek, T, \& Jackson, GL. (2004). Log sort yard economics, planning, and feasibility (General Technical Report FPL-GTR-146). Madison, WI, USA: U.S. Department of Agriculture, Forest Service, Forest Products Laboratory.

Folkard, S, \& Tucker, P. (2003). Shift work, safety and productivity. Occupational Medicine, 53, 95-101.

Gellerstedt, S. (1997). Job-rotation rosters for mechanised operations (LIRO Report Volume 22, Number 10). Rotorua, New Zealand: Logging Industry Research Organisation.

Golsse, J-M. (1991). Effects of shift length on hourly productivity: a preliminary review (1991: Aug/Sept). Canadian Forest Industries (pp. 34-39).

Hanna, AS, Taylor, CS, \& Sullivan, KT. (2005). Impact of extended overtime on construction labour productivity. Journal of Construction Engineering and Management, 131(6), 734-739.

Kerin, A, \& Carbone, J. (2003). Financial opportunities in extended hours operations: Managing costs, risks, and liabilities. Lexington, MA, USA: Circadian Technologies.

Kirk, P. (1998). The impact of shift length on processor operator fatigue (LIRO Report Volume 23, Number 18). Rotorua, New Zealand: Logging Industry Research Organisation.

Maxwell, D. (1982). A production analysis of the night shift in a forest operation. Canada: B. Sc. Thesis. University of New Brunswick

McKerchar, A, \& Twaddle, A. (1987). Central log yards - an option to consider (LIRA Technical Release. Volume 9, Number 2). Rotorua, New Zealand: Logging Industry Research Association.

Mitchell, D. (2008). Extended working hours in the Southeastern logging industry. PhD thesis. Auburn, AL, USA: Auburn University.

Murphy, G. (2002). Worldwide experience with mechanization and value recovery. In Wood for Africa 2002 Conference, Pietermaritzburg, South Africa. Corvallis, Oregon: Oregon State University, College of Forestry.

Murphy, G, \& Vanderberg, M. (2007). Modelling the economics of extended shift and 24/7 forest harvesting. New Zealand Journal of Forestry, 14-19.

Nevison, J. (1992). White collar project management questionnaire report. Concord, MA, USA: Oak Associates.

Nicholls, A, Bren, L, \& Humphreys, N. (2004). Harvester productivity and operator fatigue: working extended hours. International Journal of Forest Engineering, 15(2), 57-65.

Passicot, P, \& Murphy, G. (2013). Effect of work schedule design on productivity of mechanised harvesting operations in Chile. New Zealand Journal of Forestry Science, 43(2). http://www.nzjforestryscience.com/content/43/1/2. Accessed 4 November 2013.
Rose, K, Visser, R, \& Guild, B. (2007). Analysis of shift pattern effect on productivity at the Kaingaroa Central Processing Plant. Vienna, Austria: Austro2007/ FORMEC'07: Meeting the Needs of Tomorrows' Forests: New Developments in Forest Engineering.

Vernon, HM. (1921). Industrial fatigue and efficiency. New York, USA: George Routledge \& Sons, Ltd.

doi:10.1186/s40490-014-0019-2

Cite this article as: Murphy et al:: Time of day impacts on machine productivity and value recovery in an off-forest central processing yard. New Zealand Journal of Forestry Science 2014 44:19.

\section{Submit your manuscript to a SpringerOpen ${ }^{\odot}$ journal and benefit from:}

- Convenient online submission

- Rigorous peer review

- Immediate publication on acceptance

- Open access: articles freely available online

- High visibility within the field

- Retaining the copyright to your article

Submit your next manuscript at $>$ springeropen.com 